\title{
Teoría de la imputación de responsabilidad. Empresa criminal conjunta ${ }^{1}$
}

Emiro Vieda Silva ${ }^{2}$

El Derecho se aprende estudiando, pero se ejerce pensando

Eduardo J. Couture

\section{INTRODUCCIÓN}

El desarrollo del presente documento se basa en la teoría de la Joint Criminal Enterprise o empresa criminal conjunta, la cual es mencionada en el Estatuto Penal para Yugoslavia y desarrollada por el Tribunal Penal Internacional para la antigua Yugoslavia, que se quiere poner en evidencia o aplicar directamente al caso colombiano (los grupos de delincuencia organizada y los grupos guerrilleros).

Es importante agregar que el estudio de esta teoría propuesta pone de manifiesto su exigencia en una especie de dolo directo, que no radica en el aspecto objetivo de la conducta sino en el fin común, en el hecho de compartir dicho fin y de contribuir de forma directa a la consumación de los crímenes, materia del plan común. En este caso, se discute sobre las situaciones que ocurren actualmente en el país buscando tipificar estos actos a partir de las situaciones que han sido ya juzgadas en, o por, el Tribunal Penal Internacional para la ex Yugoslavia.

1 Este trabajo hace parte del proyecto de investigación «Teoría de imputación de responsabilidad penal: la autoría mediata por dominio de la voluntad mediante aparatos organizados de poder aplicable a crímenes de lesa humanidad».

2 Aspirante a Doctorado en Derecho, Universidad Santo Tomás. Correo electrónico: emiroviedasilva@hotmail.com 


\section{EVOLUCIÓN DE LA JURISPRUDENCIA: TEORÍA DE LA IMPUTACIÓN DE RESPONSABILIDAD PENAL INTERNACIONAL}

La teoría de la empresa criminal conjunta (Joint Criminal Enterprise en inglés), en adelante ECC, se registra por lo general como un instrumento para perseguir y enjuiciar, de forma individual, a aquellas personas que cometen crímenes de carácter internacional.

Esta teoría hace énfasis en la exigencia de una especie de dolo directo, que no radica en el aspecto objetivo de la conducta sino en el fin común, en el hecho de compartir dicho fin y de contribuir en forma directa en la consumación de los crímenes, materia del plan común. Esta doctrina, según el profesor Kai Ambos (2007), tiene una función conceptual y se ve afectada por algunos de los principios fundamentales del derecho internacional, al tiempo que invade el ámbito de la responsabilidad en los casos de mando o del superior.

La teoría se explicó por primera vez ${ }^{3}$ en una sentencia de la Sala de Apelaciones del Tribunal Penal Internacional para la ex Yugoslavia (en adelante TPIY), un cuerpo de la Organización de las Naciones Unidas establecido en cumplimiento de la Resolución 827 de 1993 «con la finalidad exclusiva de enjuiciar a los presuntos responsables de graves violaciones del derecho internacional humanitario, cometidas en el territorio de la ex Yugoslavia entre el 1 de enero de 1991 y una fecha que el Consejo de Seguridad determinará una vez restaurada la paz» (Consejo de Seguridad ONU, 1993b) ${ }^{4}$. El aporte importante de esta teoría en materia de imputación de delitos, con significado en los comportamientos de los superiores jerárquicos, surgió como consecuencia de la discusión dada dentro de caso Prosecutor [El Fiscal] v. Dusko Tadic ${ }^{5}$.

3 La fecha exacta fue el 15 de julio 1999.

4 Este documento y las sentencias del TPIY que se mencionan en este ensayo se encuentran disponibles en Internet en la página web de la Biblioteca Dag Hammarskjöld de las Naciones Unidas, dentro de los documentos históricos del Consejo de Seguridad.

5 «Duško Tadić ([nacido el] 1 de octubre de 1955 en Bosnia-Herzegovina), fue una autoridad serbobosnia a quien se le formularon cargos por crímenes contra la humanidad (12), graves violaciones a los convenios de Ginebra (12), y a las prácticas convencionales de la guerra (10), por sus acciones en la región de Prijedor, incluido Omarsaka, Trnopolje y los campos de detención de Keraterm durante la guerra de Yugoslavia. Tadic fue arrestado por la policía alemana en Múnich en 1994. El Tribunal Penal Internacional para la antigua Yugoslavia encontró a Tadic culpable de 12 de los 34 cargos formulados, a los que previamente se había declarado inocente de todos ellos. Dusko Tadic fue condenado a 20 años de prisión tras no mostrar ninguna señal de arrepentimiento por sus actos y "no 
El TPIY, por intermedio de su Sala de Apelaciones - a partir de la jurisprudencia anterior y del propio Estatuto aplicable 6 , planteó una teoría que involucra autoría y participación como formas de responsabilidad individual relacionadas con crímenes internacionales, que además tuviera en cuenta la forma del contexto colectivo, generalizado y sistemático en el que se cometieron tales crímenes, para superar las dificultades que surgen en materia probatoria al momento de demostrar los hechos delictivos de los intervinientes.

En este sentido, la Sala reconoció que «la mayoría de estos crímenes constituyen manifestaciones de criminalidad colectiva, ya que son cometidos con frecuencia por grupos o por individuos que actúan en cumplimiento de un designio común criminal» (p. 1$)^{7}$.

Aunque el Tribunal no halló ninguna base legal explícita de intervención delictiva, a través de la ECC inferida del Estatuto sí la encontró en forma implícita —en el término cometidos-, teniendo en cuenta que la comisión de los crímenes también podría consumarse a través de la intervención en la realización del propósito o designio común.

El TPIY también reconoció que al momento de la consumación del crimen existió una división de tareas propias de diferentes formas de coautoría, en la que unas personas ejecutaron la conducta ilícita mientras que otro número ejecutó acciones encaminadas a facilitar y contribuir a la terminación de la misma. Acerca de la dimensión de estas responsabilidades, en la jurisprudencia del caso Tadic se afirma que «la gravedad de semejante participación es frecuentemente no menor de aquella de los que realmente llevan a cabo los actos en cuestión» (2014).

haber cooperado de ninguna manera relevante con el Fiscal del Tribunal”, aunque en la apelación de la sentencia fue encontrado culpable de más cargos. La pena es cumplida actualmente en Alemania» («Duško Tadić», artículo disponible en http://es.wikipedia.org/wiki/ Duško_Tadić).

6 El Estatuto Internacional adoptado por el Consejo de Seguridad de la Naciones Unidas para el TPIY.

7 Así, un aspecto de gran trascendencia en esta forma de responsabilidad parte del punto de vista de la macrocriminalidad, que comprende fundamentalmente comportamientos conforme al sistema y adecuados a la situación dentro de una estructura de organización, aparatos de poder u otros contextos de acción colectiva, y se sustenta en la concepción de los crímenes internacionales tal y como ha sido consagrada en los artículos 6 a 8 del Estatuto de Roma. La existencia fáctica de grupos no estatales que cometen crímenes internacionales es, en opinión del autor, el argumento decisivo a favor de una comprensión más exacta del concepto. Una sentencia reciente en el mismo sentido es El Fiscal v. Krajisnik (Sentencia de Primera Instancia), IT-00-39-T, Tribunal Penal Internacional para la ex Yugoslavia (TPIY), 27 de septiembre de 2006, $\$ 876$. Sobre la capacidad de la CCE de aprehender las distintas formas de macrocriminalidad, véase Van Der Marchitez (2007, pp. 91-108). 
De acuerdo con lo anterior, afirma el TPIY que pudiendo considerar como autores materiales a aquellos que ejecutan directamente la acción, no puede desconocerse el atributo de coautores de quienes hubieran permitido que el perpetrador llevara a cabo el hechos, tal como se observa en la TPIY del 15 de julio de 1999 (Sentencia de la Sala de Apelaciones, IT-94-1-A).

En el Artículo $7^{\circ}$ del Estatuto Internacional se establece la responsabilidad penal individual por la comisión de inter alia crímenes contra la humanidad:

1. Quienquiera haya planificado, incitado a cometer, ordenado, cometido, o ayudado y alentado de cualquier forma a planificar, preparar o ejecutar uno de los crímenes contemplados en los artículos 2 a 5 del presente Estatuto, es individualmente responsable de dicho crimen.

3. El hecho de que cualquiera de los actos contemplados en los artículos 2 a 5 del presente Estatuto haya sido cometido por un subordinado, no libera a su superior de su responsabilidad penal si sabía o tenía razones para saber que el subordinado se aprestaba a cometer ese acto o ya lo hizo, y que el superior no tomó las medidas necesarias y razonables para impedir que dicho acto no fuera cometido, o para castigar a los autores.

4. El hecho de que un acusado haya actuado en ejecución de una orden de un gobierno o de un superior no lo exonera de su responsabilidad penal, pero puede ser considerado como un motivo de disminución de la pena si el Tribunal Internacional lo estima conforme a la justicia ${ }^{8}$ (Consejo de Seguridad ONU, art. 7, 1993a).

En el mismo sentido, el Estatuto de Roma de la Corte Penal Internacional — aprobado el 17 de julio de 1998-, en su artículo 25.3, se refiere a la responsabilidad penal individual de la siguiente forma:

3. De conformidad con el presente Estatuto, será penalmente responsable y podrá ser penado por la comisión de un crimen de la competencia de la Corte quien:

b. Cometa ese crimen por sí solo, con otro o por conducto de otro, sea éste o no penalmente responsable;

c. Ordene, proponga o induzca la comisión de ese crimen, ya sea consumado o en grado de tentativa;

8 El Estatuto del Tribunal Penal Internacional para Ruanda en su Artículo 6 expresa la forma de responsabilidad individual en los mismos términos. Adicionalmente véase Ramelli (2011). 
d. Con el propósito de facilitar la comisión de ese crimen, sea cómplice o encubridor o colabore de algún modo en la comisión o la Tentativa de comisión del crimen, incluso suministrando los medios para su comisión;

e. Contribuya de algún otro modo en la comisión o tentativa de comisión del crimen por un grupo de personas que tengan una finalidad común. La contribución deberá ser intencional y se hará:

i) Con el propósito de llevar a cabo la actividad o propósito delictivo del grupo, cuando una u otro entrañe la comisión de un crimen de la competencia de la Corte; o

ii) A sabiendas de que el grupo tiene la intención de cometer el crimen (Corte Penal Internacional, 1998).

Acerca del espíritu de la norma, el TPIY (1999) describe:

[E]l Estatuto no se limita a disponer jurisdicción sobre aquellas personas que planean, instigan, ordenan, perpetran físicamente un crimen o, en alguna otra forma, ayudan o alientan en su planeación, preparación o ejecución. El Estatuto no se detiene allí. No excluye aquellos modos de participación en la comisión de crímenes que ocurren cuando varias personas que tienen un propósito común se embarcan en una empresa criminal que es, entonces, llevada a cabo ya sea conjuntamente o por algunos miembros de esta pluralidad de personas. Quienquiera que contribuya a la comisión de los crímenes por el grupo de personas, o algunos miembros del grupo, en la ejecución de un propósito criminal común puede ser considerado como penalmente responsable, sujeto a ciertas condiciones (párrafo 190).

El Tribunal considera penalmente responsable no solo a la persona que materialmente ejecuta el acto delincuencial, sino también a los individuos que, en alguna forma, hicieron posible que se llevara a cabo este acto:

[E]l tener por penalmente responsable como perpetrador sólo a la persona que materialmente realiza el acto criminal sería no considerar el papel como coperpetradores de todos aquéllos que en alguna forma hicieron posible que el perpetrador físicamente llevara a cabo ese acto criminal. Al mismo tiempo, dependiendo de las circunstancias, el tener a estos últimos como responsables solamente como ayudantes y alentadores puede subestimar el grado de su responsabilidad criminal (párrafos 191-192).

Cuando la discusión se centró en establecer si la participación en una empresa criminal conjunta es una forma de comisión, más que una forma de responsabilidad

9 Adicional a esta sentencia se encuentra la del TPIY del 17 de enero de 2005, párrafo 695 y que fue citada en la Sala de Apelaciones en el caso Tadic. 
por complicidad, fue resuelta en el sentido de que el acusado es un perpetrador $y$, en muchos casos, se presenta como un co-perpetrador, más que un cómplice, lo que tiene incidencia al momento de apreciar el grado de culpabilidad, pues la pena es menor para el cómplice que para el perpetrador y/o coperpetrador. Con respecto a la discusión acerca de si esta forma de comisión se puede inferir del derecho internacional consuetudinario, el Tribunal ha sostenido:

[L]a Sala de Apelaciones sostiene la opinión que la noción de diseño común como una forma de responsabilidad por complicidad está firmemente establecida en el derecho internacional consuetudinario y adicionalmente es sostenida, aunque de manera implícita, en el Estatuto del Tribunal Internacional (TPIY, 1999, párrafo 220).

La disposición [del Artículo 7 numeral 1 del Estatuto] enumera las formas de conducta criminal que, siempre que todas las demás condiciones necesarias sean satisfechas, pueden dar como resultado que una persona acusada incurra en responsabilidad penal individual por uno o más crímenes que se disponen en el Estatuto. El artículo 7(1) del Estatuto no hace referencia explícita a la 'empresa criminal conjunta'. Sin embargo, la Sala de Apelaciones ha sostenido previamente que la participación en una empresa criminal conjunta es una forma de responsabilidad que existía en derecho internacional consuetudinario en ese momento, es decir, en $1992^{10}$.

[E]sta forma de responsabilidad [empresa criminal conjunta] [...] está establecida en el Derecho Internacional Consuetudinario [...] (TPIY, 2004c, párrafo 33).

\section{CATEGORÍAS DE CRIMINALIDAD EN LA EMPRESA CRIMINAL CONJUNTA}

Tomando como base principal la jurisprudencia relativa a los crímenes cometidos durante la Segunda Guerra Mundial, el Tribunal distinguió tres formas o categorías de criminalidad colectiva a través de la ECC:

10 Al respecto se pueden consultar algunas sentencias del TPIY: TPIY-98-32-A, (TPIY, 25 de febrero de 2004, párrafo 95) y TPIY-97-25-A, (TPIY, 17 de septiembre de 2003, párrafo 29). 


\section{Primera categoría: básica}

Esta categoría es aquella en la que todos los participantes en la ECC comparten la misma intención criminal. El Tribunal ha sostenido acerca de esta categoría:

La primera categoría es una forma 'básica' de la empresa criminal conjunta. Está representada por casos en los que todos los coperpetradores, que actúan conforme a un propósito común, poseen la misma intención criminal. Un ejemplo de ello es un plan formulado por los participantes en la empresa criminal conjunta para asesinar en donde, aunque cada uno de los participantes pueda ejercer un papel diferente, cada uno de ellos tiene la intención de asesinar (TPIY, 2004c, párrafos 33 y 97$)^{11}$.

La primera categoría está representada por casos donde todos los coacusados, actuando conforme a un diseño común, en este caso, poseen la misma intención criminal; por ejemplo, la formulación de un plan entre los coperpetradores para asesinar, donde, al llevar a cabo este diseño común (y aún si cada coperpetrador lleva a cabo un papel diferente dentro del mismo), todos ellos poseen sin embargo la intención de asesinar. Los prerrequisitos objetivos y subjetivos para imputar responsabilidad penal a un participante que no haya, o de quien no se puede probar que haya, realizado los asesinatos son los siguientes: (i) el acusado debe participar voluntariamente en un aspecto del diseño común (por ejemplo, infringiendo violencia no fatal a la víctima, o proporcionando asistencia material para o facilitando las actividades de sus coperpetradores); y (ii) el acusado, aún si no efectúa personalmente la matanza, debe sin embargo pretender este resultado (TPIY, 1999, párrafo 196).

En el primer tipo de empresa criminal conjunta el acusado tiene la intención de perpetrar un crimen y esta intención es compartida por todos los coperpetradores (TPIY, 2005d, párrafo 511).

La primera categoría es aquella en la que todos los participantes en la empresa criminal conjunta comparten la misma intención criminal. Para establecerla, debe demostrarse que el acusado debe haber (i) participado voluntariamente en uno de los aspectos del diseño criminal común; y (ii) pretendía el resultado criminal, aún si personalmente no lo llevó a cabo (TPIY, 2003c, párrafo 157).

11 Véase además Ramelli (2011, p. 485). 


\section{Segunda categoría: sistémica}

Esta segunda categoría es una variante de la básica, que se caracteriza por la existencia de un sistema organizado de maltrato, por ejemplo, casos de exterminio o de campos de concentración ${ }^{12}$ :

La segunda forma de empresa criminal conjunta, la forma 'sistémica', una variante de la primera forma, se caracteriza por la existencia de un sistema criminal organizado, en particular en el caso de campos de concentración o detención. Esta forma de empresa criminal conjunta requiere el conocimiento personal de un sistema organizado y la intención de seguir adelante con el propósito criminal de ese sistema ${ }^{13}$.

La segunda categoría es una forma 'sistémica' de empresa criminal conjunta. Es una variante de la forma básica, caracterizada por la existencia de un sistema organizado de maltrato. Un ejemplo es el exterminio o los campos de concentración, en los que los prisioneros son asesinados o maltratados conforme una empresa criminal conjunta (TPIY, 2004a, párrafo 98).

La segunda categoría distintiva de casos es, en muchos aspectos, similares a la que se señala anteriormente, y comprende los llamados casos de 'campos de concentración'. La noción de propósito común fue aplicada a instancias en las que se alegaba que las ofensas incluidas en el Acta de Acusación habían sido cometidas por miembros de unidades militares o administrativas tales como las que administraban los campos de concentración; esto es, los grupos de personas que actuaban conforme a un plan concertado [...] Esta categoría de casos [...] es realmente una variable de la primera categoría (TPIY, 1999, párrafos 202-203).

En el segundo tipo, que comprende los llamados casos de 'campo de concentración', o [empresa criminal conjunta] sistemática, el acusado tiene conocimiento de la naturaleza de un sistema de represión, en cuya aplicación participa, y de la intención de avanzar el diseño común concertado para maltratar a los internos de un campo de concentración. En tales casos, la intención requerida puede también ser susceptible de inferirse mediante prueba de que se tenía conocimiento de los crímenes que se perpetraban en el campo y de la participación continua en la

12 En opinión del autor, la retención de miembros de las Fuerzas Armadas por parte de grupos insurgentes - Farc, EPL, ELN - puede constituir esta forma de comisión. Véase Ramelli (2011, p. 488 y ss) y Aponte (2010, p. 277 y ss). 
operación del campo, así como de la posición de autoridad sostenida por una persona acusada en el campo (TPIY, 2005d, párrafo 511).

Conforme a la segunda categoría, la Fiscalía necesita demostrar que el acusado (i) conocía personalmente el sistema para maltratar a las personas detenidas, y (ii) tenía la intención de promover este sistema (TPIY, 2003c, párrafo 157).

Dentro de esta modalidad de ECC no se requiere de un acuerdo. Tal afirmación fue sustentada por el Tribunal de la siguiente manera:

En la Sentencia de Apelación del caso Krnojelac, la Sala de Apelaciones confirmó que la forma sistémica de empresa criminal conjunta no requiere prueba de un acuerdo: La Sala de Apelaciones considera que, al requerir prueba de un acuerdo en relación con cada uno de los crímenes cometidos con un propósito común, cuando se ha verificado la intención de participar en una forma sistémica de empresa criminal conjunta, la Sala de Primera Instancia fue más allá del criterio establecido por la Sala de Apelaciones en el caso Tadic. En vista que las conclusiones de la Sala de Primera Instancia demostraron que el sistema empleado en KP Dom [Complejo de Prisión en Foca] perseguía sujetar a las personas detenidas noserbias a condiciones de vida inhumana y a maltrato por motivos discriminatorios, la Sala de Primera Instancia debería haber examinado si Krnojelac sabía o no del sistema y si lo aceptó, sin que fuera necesario establecer que había concertado un acuerdo con los guardias y soldados, 'los principales perpetradores de los crímenes cometidos conforme al sistema' para cometer dichos crímenes (TPIY, 2005b, párrafos 118-119) ${ }^{14}$.

14 (TPIY,28 de febrero de 2005, párrafos 118-119) «Consecuentemente, los argumentos de los Apelantes concernientes en la inexistencia de un acuerdo deben de ser desechados» (TPIY, 17 de septiembre de 2003, párrafo 96). En (TPIY, 28 de febrero de 2005, párrafo 209): «Para circunscribir la responsabilidad de una persona acusada por participar en una segunda categoría de empresa criminal conjunta como co-perpetrador, es menos importante demostrar que existió un acuerdo más o menos formal entre todos los participantes, que demostrar su involucramiento en el sistema. Una vez que se ha establecido que el acusado tenía conocimiento del sistema de maltrato discriminatorio, es cuestión de determinar su involucramiento en este sistema, sin que se haga necesario establecer que había concertado un acuerdo con los perpetradores principales de los crímenes cometidos bajo ese sistema. La Sala de Apelaciones considera que la Sala de Primera Instancia no erró en la aplicación del derecho al no requerir prueba de un acuerdo formal entre los coperpetradores para participar en la empresa criminal conjunta». En (TPIY, 17 de septiembre de 2003, párrafo 96): «La Sala de Apelaciones hace notar que, con respecto a los crímenes considerados dentro de una forma sistémica de empresa criminal conjunta, la intención de los participantes, distinta de los autores principales, presupone un conocimiento personal del sistema de maltrato (demostrado mediante algún testimonio explícito o mediante una inferencia razonable de la posición de autoridad del acusado) y la intención de promover el sistema concertado de maltrato. Utilizando estos criterios, es menos importante probar que hubo un acuerdo más o menos formal entre todos los participantes, que demostrar su involucramiento en el sistema». (TPIY, 17 de octubre de 2003, párrafo 158): 


\section{Tercera categoría: extendida}

El Tribunal se expresó de la siguiente forma sobre esta categoría ${ }^{15}$ :

La tercera, forma 'extendida' de empresa criminal conjunta, implica responsabilidad por crímenes cometidos más allá del propósito común pero que, sin embargo, son una consecuencia natural y previsible del propósito común. El mens rea requerido para la forma extendida es de doble. Primero, el acusado debe tener la intención de participar en y contribuir con el propósito criminal común. Segundo, para poder ser considerado como responsable por crímenes que no eran parte del propósito criminal común, pero que sin embargo fueron una consecuencia natural y previsible de éste, el acusado debe también tener conocimiento de que dicho crimen podía ser perpetrado por un miembro del grupo, y voluntariamente haber tomado el riesgo de que el crimen pudiera ocurrir al unirse o al continuar participando en la empresa.

La tercera categoría es una forma 'extendida' de empresa criminal conjunta. Se refiere a casos que involucran un propósito común para cometer un crimen en el que uno de los perpetradores comete un acto que, aunque está fuera del propósito común, es, sin embargo, una consecuencia natural y previsible de la realización del propósito común. Un ejemplo de ello es el propósito común o el plan por parte de un grupo de retirar por la fuerza y a punta de pistola a miembros de una etnia de su pueblo, villa o región (para efectuar 'limpieza étnica') con la consecuencia de que, al así hacerlo, una o más de las víctimas son baleadas y asesinadas. Aunque el asesinato no pueda haber sido explícitamente reconocido como parte de un propósito común, era sin embargo previsible que la remoción forzosa de civiles

\footnotetext{
«Respecto a la segunda categoría de empresa criminal conjunta, la Sala de Apelaciones en el caso Krnojelac sostuvo que la prueba de la existencia de un acuerdo formal o informal entre los participantes no es crucial». Pero véase (TPIY, 17 de septiembre de 2003, párrafo 31): «La Sala de Apelaciones [en el caso Tadic] declara que el actus reus de este modo de participación en uno de los crímenes previstos en el Estatuto es común en cada una de las tres categorías de casos señalados arriba y [requiere, inter alia] [...] La existencia de un plan, diseño o propósito común que constituye o involucra la comisión de un crimen previsto en el Estatuto». A su vez (TPIY, 17 de enero de 2005, párrafo 698): «Para determinar que se incurrió en responsabilidad penal individual por participar en una empresa criminal conjunta, bajo alguna de las tres categorías [requiere, inter alia] [...] la existencia de un plan, diseño o propósito común [...]». Se declara de forma similar en (TPIY, 30 de noviembre de 2005, párrafo 511); (TPIY, 29 de junio de 2004, párrafo 32); (TPIY, 17 de octubre de 2003, párrafo 156); (TPIY, 31 de julio de 2003, párrafo 435).
} 
por este medio de agresión, bien podía resultar en las muertes de uno o más de dichos civiles ${ }^{16}$.

[...] [En el ejemplo anterior, 1]a responsabilidad penal puede imputarse a todos los participantes dentro de la empresa común, donde el riesgo de que ocurra una muerte era tanto una consecuencia predecible de la ejecución del diseño común y el acusado fue imprudente o indiferente respecto a ese riesgo. Otro ejemplo es aquel del plan común para desalojar por la fuerza a los civiles que pertenecen a un grupo étnico particular de sus hogares, quemando sus casas; si algunos de los participantes en el plan, al ser llevado a cabo éste, asesinan a civiles al incendiar sus casas, todos los demás participantes en el plan son penalmente responsables por el asesinato si estas muertes eran predecibles ${ }^{17}$.

\section{ELEMENTOS OBJETIVOS DE LA EMPRESA CRIMINAL CONJUNTA}

La Sala de Apelaciones [en el caso Tadic] declara que el actus reus de esta modalidad de participación en uno de los crímenes previstos en el Estatuto es común a cada una de las tres categorías de casos establecidos anteriormente y comprende los siguientes tres elementos:

i) Pluralidad de personas. No se requiere que estén organizados en una estructura militar, política o administrativa, como se demuestra claramente en los casos del Linchamiento de Essen y el de Kurt Goebell.

ii) La existencia de un plan, diseño o propósito común, que constituya o involucre la comisión de un crimen previsto en el Estatuto. No hay necesidad de que este plan, diseño o propósito haya sido previamente arreglado o formulado. El plan o propósito común puede materializarse extemporáneamente e inferirse del hecho de que una pluralidad de personas actúe al unísono para poner en marcha una empresa criminal conjunta.

iii) La participación del acusado en el diseño común que entraña la perpetración de uno de los crímenes previstos en el Estatuto. No se requiere, para tipificar esta modalidad de participación, la comisión de algún crímen específico previsto en alguna de las dichas

\footnotetext{
16 Se pronuncia de forma similar en TPIY (30 de noviembre de 2005, párrafo 511) y TPIY (25 de febrero de 2004, párrafo 99).
} 
disposiciones (el asesinato, el exterminio, torturas, violaciones, etc.), sino que puede adoptar la forma de asistencia o colaboración en la ejecución del plan o propósito común) (TPIY, 2003b, párrafo 31) ${ }^{18}$.

La doctrina de la ECC, tal como fue concebida por los magistrados que integraron los tribunales penales internacionales para la ex Yugoslavia y para Ruanda, se podría condensar en los siguientes elementos, inferidos de las decisiones más representativas (Ramelli, 2011, p.495 y ss.):

- Una pluralidad de personas, no se hace necesario que estén organizadas.

- Un plan diseñado o propósito común que entrañe la comisión de un crimen proscrito por el Estatuto.

- La participación del acusado en el plan o diseño común para perpetrar un crimen previsto en el Estatuto.

18 (TPIY, 17 de septiembre de 2003, párrafo 31): Comparar (TPIY, 1 de septiembre de 2004, párrafo 260); (TPIY, 17 de enero de 2005, párrafo 698): «Para determinar la responsabilidad penal individual correspondiente a una empresa criminal común en cualquiera de las tres categorías, los elementos que deben establecerse son: (i) una pluralidad de personas; (ii) la existencia de un plan, diseño o propósito común que constituya o involucre la comisión de un crimen previsto en el Estatuto; y (iii) la participación del acusado en el plan común que entrañe la perpetración de uno de los crímenes proscritos por el Estatuto». Se declara de forma similar en (TPIY, 30 de noviembre de 2005, párrafo 511); (TPIY, 29 de junio de 2004, párrafo 32) acerca de los mismos elementos relativos al crimen de persecución. (TPIY, 17 de octubre de 2003, párrafo 156): «Para tipificar una empresa criminal conjunta es necesario probar los siguientes elementos: - una pluralidad de personas, no necesariamente organizadas; - un plan, diseño o propósito común (que entrañe la comisión de un crimen proscrito por el Estatuto); - la participación del acusado en el plan o diseño común para perpetrar un crimen previsto en el Estatuto; - una intención compartida entre todos los participantes, de hacer avanzar en el plan o diseño común que entraña la comisión de un crimen; - que el acusado, incluso si no cometió personalmente el crimen, pretendiera el resultado .Además, en el caso de persecución, es necesario demostrar que todos los participantes en el plan común, incluida el acusado, tenían una intención discriminatoria». (ICTY-98-30/1-A, en (TPIY, 2 de noviembre de 2001, párrafo 312): Para la responsabilidad en una empresa criminal común, «una persona acusada debe haber llevado a cabo actos que hayan asistido substancialmente o afectado significativamente en el avance de los objetivos de la empresa, con el conocimiento que sus actos u omisiones facilitaron los crímenes cometidos a través de la empresa, para incurrir en responsabilidad penal por su participación en una empresa criminal común». Al respecto, comparar (TPIY, 1 de septiembre de 2004, párrafo 260): «Tanto en la primera y tercera categorías de [empresa criminal común], la fiscalía debe demostrar: 1. Una pluralidad de personas; responsabilidad individual (Artículo 7(1)); 2. la existencia de un plan, diseño o propósito común ('plan común') que constituye o involucra la comisión de un crimen dispuesto en el Estatuto; y 3. la participación del acusado en el plan común que comprende la perpetración de uno de los crímenes a los que se refiere el Estatuto» (se agrega énfasis). Para la discusión respecto a si se requiere prueba de un plan o propósito común para el segundo tipo de empresa criminal conjunta, véase Compendio del TPIY, sección (V)(e)(iii)(2)(i): «excepción: el segundo tipo de empresa criminal conjunta ('sistémica') no requiera prueba de un acuerdo». 
- Una intención compartida entre los participantes de hacer avanzar en el plan o diseño común que entraña la comisión de un crimen.

- Que el acusado, incluso si no cometió personalmente el crimen, pretendiera el resultado.

El elemento pluralidad de individuos exige que dos o más individuos unan fuerzas voluntariamente para planear o cometer un crimen. De esta manera, cuando dos o más personas acuden a cometer un crimen, se puede hablar de un contrato tácito entre sus miembros para ejecutar esta acción delictiva. Para fundar la presencia de una pluralidad de sujetos no se requiere que el arreglo preliminar o acuerdo de los contribuyentes en la ECC sea expreso; este puede ser inferido de las circunstancias.

En este punto es importante hacer énfasis en algunos aspectos de estos elementos, con el apoyo de sentencias del TPIY.

Una «pluralidad» de personas no implica que estén organizadas. Sobre este punto el Tribunal Penal Militar sostuvo que se requiere una pluralidad de personas que no tienen porqué pertenecer a alguna estructura administrativa militar, económica o política, siempre que se pongan libremente de acuerdo para cometer uno o más delitos ${ }^{19}$ :

El actus reus de participante en una empresa criminal conjunta es común a cada una de las tres categorías anteriores [...]. Primera, se requiere una pluralidad de personas (TPIY, 25 de febrero de 2005, párrafo 100).

El primer elemento que debe establecerse es que participó una pluralidad de personas en la empresa criminal conjunta ${ }^{20}$.

Al mismo tiempo, el Tribunal hizo mención a que las personas no necesitan estar organizadas en una estructura militar, política o administrativa: «Pluralidad de personas. No se requiere que estén organizados en una estructura militar, política o administrativa, como se demuestra claramente en los casos del Linchamiento de Essen y el de Kurt Goebell» ${ }^{21}$.

19 Al respecto se pueden consultar las sentencias (TPIY, 15 de julio de 1999, párrafo 227); (TPIY, 17 de septiembre de 2003, párrafo 31); (TPIY, 25 de febrero de 2004, párrafo 100); (TPIY, 28 de febrero de 2005, párrafo 64) y (TPIY99-36-A, del TPIY, 3 de abril de 2007, párrafo 364).

20 Sin embargo se debe tener claridad en que algunas de las sentencias en referencia al asunto son: (TPIY, 17 de enero de 2005, párrafo 708); (TPIY, 28 de febrero de 2005, párrafo 96; (TPIY, 17 de septiembre de 2003, párrafo 31); (TPIY, 30 de noviembre de 2005, párrafo 511; (TPIY, 17 de enero de 2005, párrafo 698); (TPIY, 29 de junio de 2004, párrafo 32); (TPIY, 17 de octubre de 2003, párrafo 156), además, todos requieren una pluralidad de personas.

21 Algunas sentencias en referencia son: (TPIY, 25 de febrero de 2004, párrafo 100); (TPIY, 15 de julio de 1999 , párrafo 227; y (TPIY, 1 de septiembre de 2004, párrafo 261). 
De la misma forma, sostuvo que la necesidad de establecer la existencia de un acuerdo o entendimiento común, un plan o propósito común, constituye per se un crimen (TPIY, 2005b, párrafo 117).

Desde este punto de vista se puede afirmar que es posible diferenciar la doctrina de la ECC de la referencia a la organización criminal o bandas armadas, en cuanto que esta castiga la mera incorporación voluntaria a una cierta organización con el conocimiento de que sus fines últimos o los medios que emplee son constitutivos de delito.

La doctrina de la ECC dice que el plan común tiene que estar enfocado particularmente en la encomienda de los delitos integrales de la ECC o, al menos, que la comisión de estos postrimeros sea el medio elegido para la consecución de los fines, a la que se enfoca el plan común ${ }^{22}$. La jurisprudencia en este sentido es clara. La empresa criminal conjunta requiere la existencia de un propósito común que constituya o involucre la comisión de un crimen ${ }^{23}$.

Se requiere un plan o propósito común, del que se pueda afirmar que se trata de un arreglo o convenio entre dos o más personas para cometer un crimen previsto por el Estatuto:

[E]l Plan Común necesariamente tiene que constituir, o involucrar, un entendimiento o un acuerdo entre dos o más personas de que cometerán un crimen previsto en el Estatuto (TPIY, 2004d, párrafo 342).

22 Véase al respecto: (TPIY, 15 de julio de 1999, párrafo 227); (TPIY, 17 de septiembre de 2003, párrafo 31); (TPIY, 25 de febrero de 2004, párrafo 100; (TPIY, 28 de febrero de 2005, párrafo 81); (TPIY-97-24-A, (TPIY, 22 de marzo 2006, párrafo 64); (TPIY, 3 de abril de 2007, párrafo 364).

23 Véase también, (TPIY, 15 de julio de 1999, párrafo 227): Uno de los elementos que se requiere es: «[1]a existencia de un plan, diseño o propósito común que constituya o involucre la comisión de un crimen dispuesto en el Estatuto» (énfasis omitido). (TPIY, 1 de septiembre de 2004, párrafo 262): «Debe demostrarse la existencia de un plan común que constituya o involucre un entendimiento o un acuerdo entre dos o más personas de que cometerán un crimen». Se declara de forma similar en (TPIY, 29 de noviembre de 2002, párrafo 66). (TPIY, 31 de julio de 2003, párrafo 435): «Para establecer responsabilidad penal conforme a una empresa criminal conjunta, la Fiscalía debe demostrar, en las tres categorías la existencia de un plan criminal entre dos o más personas en las que el acusado participó». Para el segundo tipo de empresa criminal conjunta, la Sala de Apelaciones en el caso Kvocka sugiere que «el establecer un sistema de maltrato puede ser considerado como la implementación de un plan criminal común». (TPIY, 28 de febrero de 2005, párrafo 262). Además, no es necesario un acuerdo formal para el segundo tipo de empresa criminal conjunta según Compendio TPIY, sección (V)(e)(iii)(2)(i): «excepción: para el segundo tipo de empresa criminal conjunta ('sistémica') no se requiere prueba de un acuerdo». 
De esta manera, se debe comprobar la existencia de un contrato o un arreglo que constituya un plan para ejecutar un crimen (TPIY, 2003c, párrafo 158). Aunque también se hace necesario que el crimen sea el resultado de un plan criminal común:

En una empresa criminal conjunta tal como la llevada a cabo en el campo de Omarska [segundo tipo de empresa criminal conjunta], es necesario demostrar que la muerte de la víctima es el resultado de la implementación de un plan criminal común, esto es, el establecimiento de un sistema de maltrato (TPIY, 2005b, párrafo 262).

El acuerdo puede no ser explicito, sino que puede inferirse del hecho de que una pluralidad de personas actúan al unísono.

[E]l Apelante alega que la Sala de Primera Instancia erró al encontrar que la existencia de un acuerdo o entendimiento, que constituya un convenio entre dos o más personas, no requería ser explícito, sino que podía inferirse también. [...] [Sin embargo, claramente resulta de la Sentencia de Apelación del Caso Tadic que '[n] o hay necesidad que de que e[1] plan, diseño o propósito haya sido previamente negociado o formulado. El plan o propósito común puede materializarse extemporáneamente y ser inferido del hecho de que una pluralidad de personas actúa al unísono para poder aplicar una empresa criminal conjunta'. La Sala de Apelaciones, en la Sentencia de Apelación del caso Furundzija, se basó en este razonamiento cuando identificó los elementos legales de la co-perpetración en una empresa criminal conjunta. La Sala de Apelaciones encuentra, por lo tanto, que el alegato del Apelante no está bien fundado y que este sub-fundamento de la apelación no procede ${ }^{24}$.

La existencia de un acuerdo o entendimiento para un plan, diseño o propósito común no requiere ser explícito, sino que puede inferirse de todas las circunstancias. La participación de dos o más personas en la comisión de un crimen en particular puede, por sí misma, establecer un entendimiento o un arreglo no hablado, que constituye un acuerdo entre ellos en ese momento y en ese lugar, para cometer ese acto criminal particular (TPIY, 2004, párrafo 108-110).

Igualmente, debe existir un entendimiento o acuerdo mutuo:

[E]l hecho de que los actos y la conducta de una persona acusada facilitara o contribuyera a la comisión de un crimen por otra persona y/o fuera asistido en la formación de la intención criminal de esa persona, no es suficiente para establecer más allá de toda duda razonable que existió un entendimiento o un convenio entre los dos para cometer ese crimen particular. Un acuerdo entre dos personas para

24 Algunas sentencias son: TPIY (25 de febrero de 2004, párrafos 108-109). En el mismo sentido, (TPIY, 17 de octubre de 2003, párrafo 158; (TPIY, 31 de julio de 2003, párrafo 435); y (TPIY, 29 de noviembre de 2002, párrafo 66. 
cometer un crimen requiere un entendimiento o arreglo mutuo con cada una para cometer un crimen (TPIY, 2004, párrafo 108-110).

Para inferir el plan común, este debe constituir la única inferencia razonable disponible, la cual debe colegirse de la prueba obrante en la investigación (TPIY, 2004d, párrafo 352).

Para deducir esta inferencia [de un entendimiento o acuerdo entre el acusado y otros señalados como miembros de la empresa criminal conjunta], esa debe ser la única inferencia razonable disponible, a partir de las pruebas (TPIY, 2004d, párrafo 353).

Ese plan común puede plasmarse imprevistamente, y corresponde ser deducido a partir del material probatorio y constituirse en la única inferencia razonable disponible.

El propósito común no requiere ser previamente arreglado o formulado; puede materializarse extemporáneamente ${ }^{25}$.

Para deducir esta inferencia [de un entendimiento o acuerdo entre el acusado y otros señalados como miembros de la empresa criminal conjunta], esa debe ser la única inferencia razonable disponible, a partir de las pruebas (TPIY, 2004d, párrafo 353).

Otro aspecto lo compone la intención al integrase al plan común, para efecto de responsabilidad penal individual.

Si el objetivo de la empresa criminal conjunta cambia, de forma tal que el objetivo cambia fundamentalmente en cuanto a naturaleza y ámbito del plan o diseño común con respecto al cual los participantes originalmente acordaron, entonces, una nueva y diferente empresa criminal conjunta ha sido establecida. En el caso de esta empresa criminal conjunta, al igual que en la empresa criminal conjunta original, deben establecerse los tres elementos para imputar la responsabilidad penal. Puede suceder que los miembros de la segunda empresa criminal conjunta sean los mismos que los de la empresa original (TPIY, 2005a, párrafos 700-701).

Alternativamente, puede ser que solo alguno de los miembros originales de la primera empresa criminal conjunta se una a la segunda empresa criminal conjunta, y entonces ello conlleve responsabilidad penal por esta empresa. Una persona solo será considerada como responsable por aquella empresa criminal conjunta en la que haya aceptado participar, conforme a la primera categoría de empresa criminal conjunta, y por las consecuencias naturales previsibles de la misma, en cuanto a la tercera categoría de empresa criminal conjunta.

25 Algunas sentencias consultadas (TPIY, 28 de febrero de 2005, párrafo 117). Véase también (TPIY, 28 de febrero de 2005, párrafos 96, 209; (TPIY, 1 de septiembre de 2004, párrafo 262). Se declara de forma similar en (TPIY, 15 de julio de 1999, párrafo 227); y en (TPIY, 17 de octubre de 2003, párrafo 158). «El plan o propósito común puede materializarse extemporáneamente [...]» (TPIY, 25 de febrero de 2004, párrafo 109) y (TPIY, 17 de enero de 2005, párrafo 699). 
Por otro lado, no se hace necesario que el plan común haya sido acordado con anterioridad a la comisión del crimen, puesto que el mismo puede adoptarse sobre la marcha ${ }^{26}$; al mismo tiempo, se hace necesario que el acuerdo a través del cual se adopta el plan sea expreso, y su existencia puede producirse en las circunstancias del caso, incluyendo el hecho de que varias personas hayan actuado de manera coordinada en la ejecución de los delitos integrantes del mismo ${ }^{27}$.

La participación puede tener varias formas, a saber:

Hay varias formas en las que una persona puede participar en una empresa criminal conjunta: (i) cometiendo personalmente el crimen convenido, como autor principal; (ii) asistiendo al autor principal en la comisión del crimen acordado como co-perpetrador, esto es facilitando la comisión del crimen con la intención de llevar a cabo la empresa; o (iii) actuando para promover o hacer avanzar un sistema particular, en el que el crimen es cometido en razón de la posición o función de autoridad del acusado y con conocimiento de la naturaleza de ese sistema y la intención de promover ese sistema (TPIY, 2005a, párrafo 702).

Los participantes [en una empresa criminal conjunta] pueden contribuir al plan común en una variedad de papeles. En efecto, el término 'participación' está ampliamente definido y puede tomar la forma de asistencia para, o contribuir con, la ejecución del plan común. La participación incluye tanto participación directa como indirecta (TPIY, 2004d, párrafo 263).

Una persona puede participar en una empresa criminal conjunta en varias formas: (i) cometiendo personalmente el crimen acordado como un autor principal; (ii) asistiendo o alentando al autor principal en la comisión del crimen acordado como coperpetrador que comparte la intención de la empresa criminal conjunta; (iii) actuando para promover un sistema particular en el que el crimen es cometido en

26 (TPIY, 15 de julio de 1999, párrafo 227); (TPIY, 17 de septiembre de 2003, párrafo 31); (TPIY, 25 de febrero de 2004, párrafo 100); (TPIY, 28 de febrero de 2005, párrafo 81); (TPIY, 22 de marzo 2006, párrafo 64); (TPIY, 3 de abril de 2007, párrafo 364).

27 (TPIY, 15 de julio de 1999, párrafo 227); (TPIY-95-17/1-A, TPIY, 21 de julio de 2000, párrafo 114); (TPIY, 17 de septiembre de 2003, párrafo 97); y (TPIY, 25 de febrero de 2004, párrafo 109). Véase también (TPIY, 28 de febrero de 2005, párrafo 96). Se declara de la misma manera en (TPIY, 25 de febrero de 2004, párrafo 100; y en (TPIY, 17 de septiembre de 2003, párrafo 31). (TPIY, 17 de enero de 2005, párrafo 698): «Para concluir que se incurrió en responsabilidad penal individual por participar en una empresa criminal conjunta, bajo cualesquiera de las tres categorías, [debe probarse, inter alia] [...] la participación del acusado en el plan común que involucre la perpetración de uno de los crímenes previstos en el Estatuto». Se declara de forma similar en (TPIY, 30 de noviembre de 2005, párrafo 511); (TPIY, 29 de junio de 2004, párrafo 32 (similar con respecto al crimen de persecución)); y en (TPIY, 17 de octubre de 2003, párrafo 156). 
razón de la posición o función de autoridad del acusado y con el conocimiento de la naturaleza de ese sistema y la intención de promoverlo ${ }^{28}$.

El participante no necesita cometer o participar físicamente en algún crimen establecido en el Estatuto:

La participación en una empresa criminal conjunta no requiere que el acusado cometa el actus reus de un crimen específico previsto en el Estatuto ${ }^{29}$.

Un participante en una empresa criminal conjunta no necesita participar físicamente en algún elemento de un crimen, en tanto los requisitos de responsabilidad, mediante la empresa criminal conjunta, se cumplan. Como lo explicó la Sala de Apelaciones en el caso Tadic, '[a]unque sólo algunos miembros del grupo pueden perpetrar físicamente el acto criminal (asesinato, exterminio, destrucción a gran escala de ciudades, pueblos o villas, etc.), la participación y contribución de los demás miembros del grupo es, a menudo, vital para facilitar la comisión de la ofensa en cuestión'. Esto es particularmente evidente con respecto a la forma sistémica de la empresa criminal conjunta en cuestión en el caso presente.

[C] ontrario al alegato de Kvocka, no es necesario encontrar a el acusado culpable del crimen de asesinato para establecer su participación en cada asesinato. Para crímenes cometidos como parte de una empresa criminal conjunta es suficiente probar, no la participación del acusado en la comisión de un crimen específico, sino la responsabilidad del acusado en la promoción del propósito criminal común. La Sala de Apelaciones encuentra que la Sala de Primera Instancia no erró al encontrar a Kvocka culpable del crimen de asesinato sin establecer su responsabilidad específica por cada asesinato cometido (TPIY, 2005b, párrafos 99, 263; TPIY, 2003b, párrafo 31).

La Sala de Apelaciones [en el caso Tadic] [requirió prueba, entre otras cosas, de que]: La participación del acusado en el diseño común que involucraba la perpetración de uno de los crímenes previstos en el Estatuto. Esta participación no necesita involucrar la comisión de alguno de los crímenes específicos conforme a alguna de dichas disposiciones (asesinato, exterminio, tortura, violación, etc.), sino que puede tomar la forma de asistencia en, o contribución a, la ejecución del plan o propósito común ${ }^{30}$.

28 Se declara de forma similar en (TPIY, 29 de noviembre de 2002, párrafo 67). (TPIY, 31 de julio de 2003, párrafo 435).

30 Véase también (TPIY, 15 de julio de 1999, párrafo 227); (TPIY, 17 de septiembre de 2003, párrafo 81): "La Sala de Apelaciones hace notar que, de acuerdo con su decisión en la Sentencia de Apelación del caso Tadic, una vez que un participante en una empresa criminal conjunta comparte la intención de esa empresa, su participación puede 


\section{El nivel de participación en la ECC habitualmente no requiere ser significativo o substancial:}

La Sala de Apelaciones hace notar que, en general, no existe un requisito específico de que el acusado realice una contribución substancial a la empresa criminal conjunta. Sin embargo, pueden existir casos específicos que requieren, como una excepción a la regla general, una contribución substancial del acusado para determinar si participó en la empresa criminal conjunta (TPIY, 2005b, párrafo 421).

[E]n general, no es necesario demostrar la naturaleza substancial o significativa de la contribución de una persona acusada a la empresa criminal conjunta para establecer su responsabilidad como co-perpetrador: es suficiente que el acusado haya cometido un acto u omisión que contribuya al propósito crimina común (TPIY, 2005b, párrafo 421).

La Sala de Primera Instancia sostuvo, en el párrafo 309 de la Sentencia de Primera Instancia, que para concluir que una persona, que trabaja en un campo de detención, donde las condiciones son abusivas, es responsable como participante en una empresa criminal conjunta, 'la participación en la empresa debe ser significativa [...] La Sala de Apelaciones ha declarado que la participación del acusado, al llevar a cabo la empresa criminal conjunta, probablemente comprometerá su responsabilidad penal como co-perpetrador, sin que sea necesario en, general, demostrar la naturaleza substancial o significativa de su contribución: es suficiente que el acusado haya cometido un acto u omisión que contribuya al propósito criminal común. Contrariamente a la regla de derecho sostenida por la Sala de Primera Instancia, los precedentes del Tribunal no requieren que la participación como co-perpetrador en una empresa criminal conjunta sea significativo, salvo que se manifieste de otra forma. A fortiori, contrario a lo señalado por Kvocka, dicha participación no requiere ser 'directa o significativa'. Los argumentos de Kvocka, por lo tanto, son rechazados en este punto (TPIY, 2005b, párrafo 187) ${ }^{31}$.

tomar la forma de asistencia o colaboración, con vistas a ejecutar el plan o propósito común. La parte involucrada no necesita cometer el crimen o crímenes establecidos en la empresa criminal conjunta física o personalmente".

31 (TPIY, 28 de febrero de 2005, párrafo 187): «La Sala de Primera Instancia en el caso Kvocka sostuvo que el grado de participación requerido debe ser 'significativo', esto es, hacer una empresa 'eficiente o efectiva'». Véase también (TPIY, 2 de noviembre de 2001, párrafo 306): «Se requiere participación 'significativa' de cualquiera que, con conocimiento, participe en la operación de un complejo de detención», rechazado en (TPIY, 28 de febrero de 2005, párrafo 187 y en el párrafo 90): «El requisito de que quien ayuda y alienta debe hacer una contribución substancial a la comisión del crimen para ser considerado como responsable se aplica, ya sea que el acusado ayude en el crimen cometido por una persona o en los crímenes cometidos por una pluralidad de personas». 
En cuanto a la discusión sobre los requisitos de contribución substancial por ayudar y alentar, para el TPIY, «no se requiere la relación de causa-efecto, pero debe tener un efecto substancial en la comisión del crimen»" ${ }^{22}$ (TPIY, 28 de febrero de 2005, párrafo 187).

En el estudio de caso en concreto, lo significativo de la participación puede ser relevante para demostrar la intención compartida:

En la práctica, la importancia de la contribución de una persona acusada será relevante para demostrar que la misma compartía la intención de perseguir el propósito común ${ }^{33}$ (TPIY, 2005b, párrafo 97).

Como excepción a este punto, el TPIY analizó el caso de quien no tenía alguna función oficial en el campo ni pertenecía al mismo, para considerarlo como responsable de ECC:

La Sala de Apelaciones es de la opinión que una persona no necesita haber tenido alguna función oficial en el campo o pertenecer al personal del campo para ser considerada como responsable como participante en la empresa criminal conjunta. Podría alegarse que la posibilidad de 'visitantes oportunistas' que ingresarán al campo y maltratarán a las personas detenidas al azar, agregaron la atmósfera de opresión y miedo prevalecientes en el campo. En la opinión de la Sala de Apelaciones, no sería apropiado tener a todo visitante al campo que cometió un crimen allí como responsable en calidad de participante en una empresa criminal conjunta. La Sala de Apelaciones mantiene la regla general de que no se requiere una contribución substancial a la empresa criminal conjunta, pero encuentra que, en el caso presente de 'visitantes oportunistas', es necesaria una contribución substancial al efecto general del campo, para establecer responsabilidad bajo la doctrina de la empresa criminal conjunta (TPIY, 2005b, párrafo 599).

Con respecto a los diferentes crímenes cometidos contra diversas personas detenidas en el campo, no puede descartarse, con base en las pruebas disponibles, que algunos de los perpetradores de los crímenes establecidos en, o con relación a, el campo de prisioneros, los cometieron solamente en calidad de visitantes que fueron al campo en ad hoc bases y, mientras estuvieron ahí, por motivaciones personales, tales como venganza, maltrataron o asesinaron a viejos enemigos. Es cierto que tales 'visitantes oportunistas' podían haberse convertido también en participantes de la empresa criminal conjunta que se alega al contribuir al efecto general del campo de prisioneros. Sin embargo, con objeto de demostrar su participación, sería necesario establecer que su contribución en la consecución del 
objeto común de la empresa criminal conjunta que se alega fue substancial (TPIY, 2005d, párrafo 667).

El nivel de participación para el que ayuda y alienta debe tener un efecto substancial.

El ámbito de la participación material es también un factor decisivo al evaluar la responsabilidad de una persona por ayudar y alentar a la comisión de los crímenes por una pluralidad de personas involucradas en una empresa criminal conjunta. [...] el que ayuda y alienta debe hacer una contribución substancial al crimen en orden de ser considerado como responsable ${ }^{34}$ (TPIY, 2 de noviembre de 2001, párrafo 289).

El participante debe llevar a cabo actos dirigidos a fomentar el plan o propósito común:

La co-perpetración en una empresa criminal conjunta, por la cual el Apelante fue encontrado culpable, requiere solamente que el acusado comparta el mens rea o 'la intención de perseguir el propósito común' y realice algunos actos que 'en alguna forma estén dirigidos a fomentar el diseño común (TPIY, 2005c, párrafo 38).

Para incurrir en responsabilidad penal, el acusado debe realizar alguna acción para contribuir a la implementación del plan común (TPIY, 2004d, párrafo 263).

Una empresa criminal conjunta requiere, además de demostrar que diversas personas estuvieron de acuerdo en cometer un crimen, que las partes en ese acuerdo adoptaran acciones para fomentar ese convenio (TPIY, 2003c, párrafo 158).

El límite preciso de participación en una empresa criminal conjunta no ha sido establecido, pero la participación debe 'en alguna forma [...] estar dirigida a fomentar el plan o propósito común (TPIY, 2001, párrafo 289).

Otro aspecto importante de la ECC relacionado con este ítem es que el participante no requiere estar físicamente presente durante la comisión del crimen:

La Sala de Apelaciones afirma que un co-perpetrador en una empresa criminal conjunta no requiere cometer físicamente parte alguna del actus reus del crimen involucrado. Ni se requiere que el participante en una empresa criminal común esté físicamente presente cuando el crimen se cometa [...] Aunque legalmente es posible que una persona acusada sea considerad[a] como responsable por la comisión de crímenes sin haber estado presente cuando se cometieron, la aplicación de esta posibilidad en un caso dado depende de las pruebas (TPIY, 2005b, párrafos 112-113; TPIY, 17 de septiembre de 2003b, párrafo 81).

34 (TPIY, 2 de noviembre de 2001, párrafo 289): "La asistencia o facilitación proporcionadas por quien ayuda o alienta debe, desde luego, tener un efecto substancial en el crimen cometido por un co-perpetrador". (TPIY, 28 de febrero de 2005, párrafo 188). 
La Sala de Apelaciones considera que no se requiere la presencia del participante en la empresa criminal conjunta en el momento en que el crimen es cometido por el autor principal para incurrir en este tipo de responsabilidad ${ }^{35}$ (TPIY, 30 de noviembre de 2005, párrafo 511).

Son igualmente responsables todos los participantes, independientemente del papel que tuvieren:

[E]l Apelante disputa la conclusión de la Sala de Primera Instancia que, si el crimen acordado es cometido por uno o más de los participantes de una empresa criminal conjunta, todos los participantes son igualmente culpables del crimen, independientemente del papel que cada uno haya tenido en su comisión [...] La Sala de Apelaciones recuerda que los precedentes del Tribunal, que derivan de la Sentencia de Apelación del caso Tadic y de la Sentencia del caso Ojdanic, consideran la participación en una empresa criminal conjunta como una forma de comisión. A la luz de estos precedentes, la Sala de Apelaciones encuentra que el Apelante no ha demostrado que la Sala de Primera Instancia erró al encontrar que todos los participantes en una empresa criminal conjunta son igualmente culpables del crimen, independientemente del papel que tuvo cada uno en su comisión (TPIY, 25 de febrero de 2005, párrafos 110-111).

Independientemente del papel que cada uno jugó en su comisión, todos los participantes en la empresa son culpables del mismo crimen (TPIY, 2005a, párrafo 702).

Cuando el crimen acordado sea cometido por uno de los participantes en la empresa criminal conjunta, todos los participantes son igualmente culpables por crimen, independientemente del papel que cada uno haya jugado en su comisión (TPIY, 2003a, párrafo 435).

Si el crimen acordado es cometido por uno u otro de los participantes en una empresa criminal conjunta, como ya se ha discutido, todos los participantes de esa empresa son igualmente culpables por crimen, independientemente del papel jugado por cada uno de ellos en su comisión (TPIY, 29 de noviembre de 2002, párrafo 67).

La mera membresía de la organización, no satisface la participación:

35 Se declara de forma similar en (TPIY, 30 de noviembre de 2005, párrafo 511). (TPIY, 17 de octubre de 2003, párrafo 158): «[La Sala de Apelaciones en el caso Krnojelac] confirmó también que la presencia al momento de cometer el crimen no es necesaria. Una persona puede ser considerada como responsable por actos criminales llevados a cabo por otros, aún sin estar presente; lo único que se requiere es que la persona forme parte de un acuerdo con otros de que el crimen se llevará a cabo». Subrayo fuera de texto. 
La responsabilidad penal individual por participar en una [empresa criminal conjunta] no surge como resultado de la mera membresía en una empresa criminal (TPIY, 2004d, párrafo 263).

La empresa criminal conjunta no es una responsabilidad por la sola membresía en una empresa criminal, ya que lo que le concierne es la participación en la comisión de un crimen, como parte de una empresa criminal conjunta (TPIY, 2003c, párrafo 158).

La Sala de Primera Instancia enfatiza que la empresa criminal conjunta no puede ser considerada como una membresía en una organización, porque esto constituiría un nuevo crimen no previsto en el Estatuto y por lo tanto constituiría una violación flagrante al principio nullum crimen sine lege. Esto debe siempre tenerse en mente cuando se trabaja con esta definición del término 'comisión' (TPIY, 2003a, párrafo 433).

No se hace necesario demostrar que la ofensa no habría ocurrido, a no ser como consecuencia de la participación del perpetrador, pero el hecho debe constituir un anillo en la cadena causal:

La Sala de Apelaciones está de acuerdo en que el Fiscal no requiere demostrar que la participación del acusado es un sine qua non, sin el cual el crimen no podría o no hubiera sido cometido. Así, el argumento de que el acusado no participó en la empresa criminal conjunta porque era fácilmente reemplazable debe ser rechazado (TPIY, 2005b, párrafos 98 y 193).

La Sala de Primera Instancia coincide con la Sala de Primera Instancia en el caso Brdjanin, en donde, aunque la participación del acusado no requiere ser una conditio sine qua non para la comisión del crimen, el involucramiento de ésta en el acto delictivo debe constituir un eslabón en la cadena de causación (TPIY, 2005a, párrafo 702).

El involucramiento de una persona acusada en el acto criminal debe de formar un eslabón en la cadena de causación. Esto significa que la Fiscalía debe al menos establecer que el acusado tomó alguna acción para fomentar el plan criminal. Sin embargo, no es necesario que la participación sea una conditio sine qua non, o de que la ofensa no habría ocurrido a no ser por la participación del acusado (TPIY, 2004d, párrafo 263).

Para determinar la participación, se hace necesario considerar las tareas reales y no el título del cargo.

[L]a Sala de Apelaciones considera que el título de auxiliar administrativo utilizado por la Sala de Primera Instancia para describir [a Prcac] no es relevante para la conclusión de que fue un co-perpetrador en la empresa criminal conjunta. La Sala de Primera Instancia no consideró que el hecho de ser un auxiliar administrativo 
fuera indicativo de responsabilidad penal. El título del cargo, se dio solamente para sumar sus tareas, que eran diferentes de aquellas de otros guardias o de sus superiores. La Sala de Primera Instancia correctamente asignó responsabilidad con base en las tareas que realmente efectuaba Prcac, y no con base en la mera etiqueta descriptiva (TPIY, 2005b, párrafo 622).

No es necesario demostrar completo acuerdo sobre los crímenes cometidos; no obstante, debe existir un plan común para cometer el crimen que se imputa.

La Sala de Primera Instancia acepta que, mientras que la ECC [empresa criminal conjunta] puede tener diversos objetivos criminales diferentes, no es necesario que la Fiscalía establezca que cada participante estuvo de acuerdo con cada uno de los crímenes cometidos. Sin embargo, si es necesario que la Fiscalía demuestre que, entre el miembro de la ECC que físicamente comete el crimen material que se imputa y la persona que es considerada como responsable según la ECC por este crimen, existía un plan común para cometer por lo menos ese crimen en particular (TPIY, 2004d, párrafo 264).

\section{ELEMENTOS SUBJETIVOS DE LA EMPRESA CRIMINAL CONJUNTA}

\section{Variantes}

Los elementos subjetivos de la doctrina de la ECC son diferentes en cada una de sus tres categorías. Por ejemplo, la variante básica demanda que todos los miembros de la ECC compartan la intención de cometer los delitos que integran el plan común ${ }^{36}$, de tal manera que cada uno de los miembros debe contribuir a la materialización del plan de una forma directa (dolo de primer grado) ${ }^{37}$; por otro lado, cuando el tipo subjetivo de tales comportamientos requiere un determinado dolo especial (dolus special), como sería el genocidio cuando el genocida tiene la intención de destruir total o parcialmente un grupo nacional, étnico, racional o religioso, o también en los crímenes de persecución contra la humanidad, cuando se tiene la intención

\footnotetext{
36 A este respecto se consultan: (TPIY, 15 de julio de 1999, párrafo 228); (TPIY, 17 de septiembre de 2003, párrafo 32); (TPIY, 25 de febrero de 2004, párrafo 101; (TPIY, 28 de febrero de 2005, párrafos 82-83); (TPIY, 22 de marzo 2006, párrafo 65); y (TPIY, 3 de abril de 2007, párrafo 365).

37 El Concepto de dolo directo de primer grado ha sido definido por la Sala de Cuestiones Preliminares de la CPI en la decisión de confirmación de cargas en el caso Lubanga. Véase Decisión sobre la confirmación de los cargos Sala de Cuestiones Preliminares I, ICC-01/04-01/06-803-Ten, 29 de enero de 2007, párrafo 352.
} 
de discriminar por motivos no permitidos por el derecho internacional, se hace necesario que cada uno de los partícipes de la ECC actúe motivado por él mismo (TPIY, 2000b, párrafo 118).

\section{Aplicaciones de las categorías}

Primera categoría. El TPIY dedujo esta primera modalidad de los hechos consistentes en trabajos forzosos en el Complejo de Prisión KP Dom en Foca, como una forma de persecución.

[L]a Sala de Apelaciones considera que Krnojelac no debe ser considerado sólo como alguien que ayudó y alentó, sino como un co-perpetrador del crimen de trabajo forzoso. La Sala de Apelaciones sostiene que Krnojelac compartía la intención de hacer que las personas detenidas no-serbias ejecutaran trabajo ilegal en condiciones tales que se encontró, era imposible que hubieran consentido libremente en la realización. La Sala de Apelaciones encuentra que la única conclusión que un juzgador de hecho razonable hubiera alcanzado era que Krnojelac era culpable como co-perpetrador de persecución, por el trabajo forzoso impuesto a las personas detenidas no-serbias por las siguientes razones: Krnojelac estaba consciente de la decisión inicial de utilizar a las personas detenidas de KP Dom [Complejo de Prisión en Foca] para trabajar, y fue responsable de todas las unidades de negocios y sitios de trabajo asociados con la prisión y, como tal, jugó un papel central. Además, Krnojelac voluntariamente aceptó el cargo con pleno conocimiento de que civiles no-serbios estaban ilegalmente detenidos en KP Dom debido a su etnicidad y sabía que ninguno de los procedimientos establecidos para detener legalmente a personas se siguió jamás para KP Dom. Ejercía el control final sobre todo el trabajo de los detenidos en y para KP Dom. Tenía reuniones regulares con los directivos de la fábrica de muebles, taller de metal y granja donde trabajaban las personas detenidas.

A la luz de lo anterior, la Sala de Apelaciones considera que Krnojelac no podía haber dejado de compartir la intención de utilizar ilícitamente para el trabajo a prisioneros no-serbios. La Sala de Apelaciones, por lo tanto, encuentra que la decisión de la Sala de Primera Instancia de absolver a Krnojelac del crimen de persecución por trabajo forzoso, debe ser revertida y que, conforme al artículo 7(1) del Estatuto, Krnojelac debe ser condenado por persecución con motivo de trabajo forzoso, como co-perpetrador de la empresa criminal conjunta cuyo objetivo era perseguir a las personas detenidas no-serbias explotándolas con trabajo forzoso (TPIY, 17 de septiembre de 2003b, párrafos 206-207).

En particular, el desplazamiento que involucró a las personas detenidas en el Complejo de Prisión KP Dom como una forma de persecución. 
Krnojelac tiene responsabilidad penal individual por los intercambios que fueron parte de la empresa criminal conjunta, en los que personalmente jugó un papel, con el fin último de desplazar forzosamente a las personas detenidas bajo su control en el KP Dom [Complejo de Prisión]. Aún, si no tenía control sobre el estado específico de la operación, aceptó el resultado final de la empresa. Por lo tanto no es necesario demostrar que personalmente participó en compilar las listas. Los 'intercambios' se iniciaron durante el verano de 1992 y continuaron por lo menos hasta marzo de 1993. Como se señaló arriba, la Sala de Apelaciones está satisfecha que las personas detenidas no-serbias fueron tomados de KP Dom con intención discriminatoria. Conforme a su propio testimonio, Krnojelac sabía que las personas detenidas estaban siendo removidas de KP Dom. Adicionalmente, la Sala de Primera Instancia estableció que, en virtud de su cargo como alcaide de la prisión, Krnojelac sabía que las personas detenidas no-serbias estaban detenidas ilícitamente como resultado de su etnicidad. Como alcaide, Krnojelac autorizó al personal de KP Dom para entregar a las personas detenidas no-serbias. Apoyó dichas remociones al permitir que las mismas continuaran. Sin encarcelamiento ilegal, no habría sido posible continuar llevando a cabo los intercambios. La Sala de Apelaciones está satisfecha de que Krnojelac compartía la intención de los perpetradores principales en la empresa criminal conjunta dirigida a remover a las personas detenidas no-serbias de KP Dom [...] La Sala de Apelaciones está convencida más allá de toda duda razonables, de que Krnojelac es responsable como co-perpetrador en una empresa criminal conjunta cuyo objetivo era perseguir a las personas detenidas de KP Dom deportándolas y expulsándolas (TPIY, 2003b, párrafos 246 y 241).

Plan común para perseguir a civiles no serbios en el municipio de Bosanski Samac:

La Sala de Primera Instancia está satisfecha, con base en la prueba, que miembros del Estado Mayor de Crisis [en Bosanski Samac], incluyendo a Blagoje Simic como Presidente; la policía serbia, incluyendo al Jefe de Policía, Stevan Todorovic, que también eran miembros del Estado Mayor de Crisis; paramilitares serbios, incluyendo a 'Debeli' (Srcko Radovanovic, 'Pukovnik'), 'Crni' (Dragan Dordevic), 'Lugar' (Slobodan Miljkovic), y 'Laki' (Predrag Lazarevic); y el 17 Grupo Táctico del JNA [Ejército Popular Yugoslavo]; eran participantes en una empresa criminal conjunta, responsable de ejecutar el plan común para perseguir a los civiles noserbios en el Municipio de Bosanski Samac.

La Sala de Primera Instancia se encuentra [...] satisfecha que, a nivel horizontal, los participantes en la empresa criminal conjunta actuaron según un plan común para establecer instituciones y autoridades para perseguir a civiles no-serbios en el Municipio de Bosanski Samac.

Existe suficientes pruebas para concluir que los participantes en la empresa criminal conjunta actuaron en unísono para ejecutar un plan que incluía la toma por la 
fuerza del pueblo de Bosanski Samac, tomando varias instalaciones e instituciones vitales en el pueblo, y persiguiendo a los civiles no-serbios en el Municipio de Bosanski Samac, dentro del periodo señalado en el Acta de Acusación enmendada. Este plan común estaba dirigido a la comisión del crimen de persecución contra no-serbios, incluyendo actos de arresto, detención o confinamiento ilegales, trato cruel e inhumano, deportación y traslado forzoso y la expedición de órdenes políticas y decisiones que violaban los derechos fundamentales de los civiles noserbios (TPIY, 2003c, párrafos 984, 986-987, 992).

Blagoje Simic, como Presidente del Estado Mayor de Crisis, fue el ápex de la empresa criminal conjunta a nivel municipal. Blagoje Simic sabía que su papel y autoridad eran esenciales para el logro del fin común de persecución. Como Presidente del Estado Mayor de Crisis y después de la Presidencia de Guerra y Asamblea Municipal, fue el civil de más alto rango en el Municipio de Bosanski Samac, y el Estado Mayor de Crisis responsable por, inter alia, la economía, cuidados humanitarios y médicos, información y propaganda, abastecimiento de provisiones de comida y comunicaciones. [...] De ahí que Blagoje Simic y el Estado Mayor de Crisis apoyaron el trabajo de la policía y paramilitares serbios, y del Grupo Táctico 17. La Sala de Primera Instancia está convencida de que Blagoje Simic y los demás participantes actuaron con la intención compartida de perseguir su objetivo común (TPIY, 17 de septiembre de 2003, párrafo 7-9 38. $^{38}$.

\section{Segunda categoría. Complejo de la prisión KP Don.}

La Sala de Primera Instancia hizo notar que, por su propia admisión, Krnojelac era alcaide del [Complejo de Prisión] de KP Dom a partir del 18 de abril de 1992 y hasta el fin de julio de 1993, es decir, por 15 meses. Encontró que Krnojelac voluntariamente tomó la posición como alcaide en funciones y después de alcaide, hasta su partida de KP Dom y que durante ese periodo retuvo todas las facultades asociadas con el cargo de alcaide previo al conflicto. Se señaló arriba que la Sala de Primera Instancia estableció que, por virtud de su posición como alcaide de la prisión, Krnojelac sabía que las personas detenidas no-serbias estaban siendo

38 Una opinión parcialmente disidente por parte del Juez Per-Johan Lindholm se encuentra en Ibíd., párrafos 7-9: «No puedo estar de acuerdo con la conclusión de la mayoría de que el Grupo Táctico 17 del JNA estuvo involucrado en la toma [...] Tampoco puedo estar de acuerdo con la Mayoría que la toma estuvo planeada y fue implementada con el propósito de perseguir a la población no-serbia [...] Considero la toma por los serbios, y el desarme de los no-serbios, como una operación armada preventiva, justificada para evitar un derramamiento de sangre interétnico o aún un baño de sangre. Estoy de acuerdo con la mayoría de que la toma per se no constituía crimen alguno. La tragedia que siguió a la toma no fue, en mi opinión de acuerdo con las pruebas presentadas en el tribunal, el resultado de algún plan previo entre determinadas personas». 
detenidas ilegalmente, admitió saber que estaban siendo detenidas precisamente porque eran no-serbias y sabía que ninguno de los procedimientos establecidos para la detención legal de personas se siguieron jamás en KP Dom. También se estableció que estaba consciente de la intención de los autores principales - los guardias y autoridades paramilitares - responsables de las condiciones de vida impuestas a las personas detenidas no-serbias en KP Dom, sabía de las golpizas y actos de tortura que se llevaban a cabo y que, al no haber adoptado las medidas apropiadas que, como alcaide, estaba obligado a adoptar, alentó a sus subordinados a mantener esas condiciones y fomentó la comisión de esos actos (TPIY, 17 de septiembre de 2003b, párrafos 110-111).

La Sala de Apelaciones sostiene que, con respecto a los deberes de Krnojelac, el tiempo durante el cual ejerció esas tareas, su conocimiento del sistema establecido, los crímenes cometidos como parte del sistema y su naturaleza discriminatoria, un juzgador de hecho debería haber razonablemente inferido, de las conclusiones anteriores, que era parte de un sistema y que, por lo tanto, intentó fomentarlo. La misma conclusión debe alcanzarse cuando se determina si las conclusiones deberían haber llevado a un juzgador de hecho a concluir razonablemente que Krnojelac compartía la intención discriminatoria por la perpetración de crímenes de encarcelamiento y actos inhumanos (TPIY, 17 de septiembre de 2003) ${ }^{39}$.

La situación personal no impide una conclusión de mens rea:

Kvocka alega que nunca tuvo la intención discriminatoria requerida, arguyendo de que está casado con una bosnio-musulmana y que tenía asociación cercana con no-serbios aún durante la guerra. Alega también que era miembro del Partido Reformista Moderado de Ante Markovic y que nunca mostró ninguna intolerancia ante otros nacionales [...] Kvocka replica que su asociación con la comunidad musulmana, su afiliación política y su deber como policía profesional son hechos que desaprueban la existencia de una intención discriminatoria [...] La Sala de Apelaciones entiende que Kvocka alega que la Sala de Primera Instancia erró al omitir considerar estas circunstancias cuando evaluó su mens rea y arguye que su situación personal no fue consistente con las conclusiones de la Sala de Primera Instancia de que él tenía la intención de promover la empresa criminal conjunta. Sería equivocado considerar que la Sala de Primera Instancia desestimó la información proporcionada por Kvocka con respecto a su llamada 'situación personal'. La Sala de Apelaciones hace notar que, en la sub-sección que trata con los antecedentes personales de Kvocka, la Sala de Primera Instancia revisó las

\footnotetext{
39 Véase Compendio TPIY, sección (V)(e)(iv)(3), donde se sugiere que la intención compartida puede no ser el mens rea para el segundo tipo de empresa criminal conjunta: «Segundo tipo ('sistémico'): necesita demostrar conocimiento personal del sistema de maltrato y de la intención de promover ese sistema».
} 
pruebas y concluyó que muchos testigos describieron a un hombre tolerante y políticamente moderado, que era cercano a la comunidad musulmana, dentro de la que se había casado. Sin embargo, en la opinión de la Sala de Apelaciones, dichas conclusiones no impiden que un juzgador de hecho razonable concluyera, a la luz de todas las pruebas proporcionadas, que el Acusado intentaba fomentar una empresa criminal conjunta cuyo propósito era perseguir a los no-serbios (TPIY, 2005b, párrafos 230, 232-233).

Tercera categoría. Los crímenes en Potocari como una consecuencia natural y previsible de la «Operación Krivaja 95»:

La Sala de Apelaciones concluyó que Radislav Krstic voluntariamente participó en la empresa criminal conjunta que resultó en una crisis humanitaria en Potocari, y estaba consciente que la natural y razonable consecuencia de esta crisis humanitaria era que se cometerían crímenes contra la población civil.

La limpieza étnica de los civiles bosnio-musulmanes de Srebrenica era parte de la operación Krivaja 95 en la cual se encontró que Krstic jugó un papel de liderazgo. Radislav Krstic sabía que los bombardeos de Srebrenica forzarían a miles de civiles bosnio-musulmanes a huir hacia Potocari debido a la presencia de las NNUU allí. También estaba consciente que había instalaciones inadecuadas en Potocari para acomodar a los civiles bosnios. Como tal, la Sala de Primera Instancia lo encontró responsable por establecer el escenario en Potocari para los crímenes que siguieron. Además de su presencia en dos reuniones convocadas por el General Mladic, en el Hotel Fontana, sabía que los civiles bosnio-musulmanes de hecho estaban enfrentando una crisis humanitaria en Potocari. Había, por lo tanto, pruebas suficientes para que la Sala de Primera Instancia estuviera satisfecha de que Radislav Krstic estaba consciente de que los civiles bosnio-musulmanes en Potocari serían sujetos a otros actos criminales.

La responsabilidad de Radislav Krstic por los crímenes cometidos en Potocari derivó de su participación individual en la empresa criminal conjunta para trasladar forzosamente a los civiles. Los crímenes oportunistas eran consecuencias naturales y previsibles de esa empresa criminal conjunta ${ }^{40}$.

En cuanto a la diferencia existente, dentro del contexto de una ECC, entre ayuda, aliento y co-perpetración, actuaciones conforme a un diseño o propósito común:

La Sala de Apelaciones hace notar que la distinción entre estas dos formas de participación ['ayuda y aliento' y 'co-perpetración en una empresa criminal conjunta'] es importante, tanto para describir adecuadamente el crimen y determinar la sentencia apropiada (TPIY, 2005b, párrafos 92).

40 Sentencia de la Sala de Apelaciones: (TPIY, 19 de abril de 2004, párrafos 239, 147, 151). 
Existen diferencias con relación a los requisitos del actus reus así como al mens rea entre ambas formas de responsabilidad penal individual [ayudar y alentar, y co-perpetración en una empresa criminal conjunta] (TPIY, 2004b, párrafos 239, $147,151)^{41}$.

A continuación se plantean algunos casos puntuales que han sido estudiados y cuestionados, para los que no es clara la posible aplicación de la doctrina y jurisprudencia:

¿Podría ser condenada una persona por crímenes mientras estuvo ausente del campo? Para resolver este punto se revisará el caso analizado en el campo de Omasarska:

Kvocka alega que la Sala de Primera Instancia sostuvo que él no era responsable por los crímenes que se cometieron en el periodo en el que estuvo ausente en el campo de [Omarska] y, por lo tanto, se debería haber considerado su horario de trabajo en el campo, para tener en cuenta los días en que estuvo franco. [...] La Sala de Apelaciones [...] hace notar que ya ha determinado que la Sala de Primera Instancia no limitó la responsabilidad de Kvocka al periodo en el que estaba físicamente presente en el campo, sino que lo tuvo como responsable por crímenes cometidos en el campo a partir del 29 de mayo al 23 de junio de 1992, esto es, durante el tiempo en el que estuvo empleado en el campo (TPIY, 2005b, párrafos 296, 298).

¿Podría ser condenada una persona por asesinato u otros delitos ocurridos antes de su llegada al campo?

Kvocka replica que ya que la Fiscalía acepta que el asesinato de [Ahil] Dedic ocurrió una cuantas horas antes de que llegara al campo por primera vez, no debería ser considerado como responsable por el asesinato [...] La Sala de Apelaciones sostiene que en vista de que la Sala de Primera Instancia no proporcionó información detallada o fundamentos de hecho convincentes, no ha quedado demostrado que el asesinato de Ahil Dedic se cometió después de la llegada de Kvocka al campo de Omarska, el límite de tiempo señalado por la Sala de Primera Instancia con respecto a la responsabilidad de Kvocka. La Sala de Apelaciones está de acuerdo con este fundamento de la apelación y encuentra que la Sala de Primera Instancia erró al encontrar a Kvocka culpable del asesinato de Ahil Dedic (TPIY, 2005b, párrafos 266, 268).

\footnotetext{
41 A este respecto (TPIY, 25 de febrero de 2004, párrafo 102). La doctrina de la empresa criminal conjunta se discute en la sección (V)(e) del Compendio del TPIY; ayudar y alentar se discuten en la sección (V)(d) del Compendio del TPIY. (TPIY, 30 de noviembre de 2005, párrafo 510). Se declara de forma similar en (Sentencia de Primera Instancia), (TPIY, 3 de marzo de 2000, párrafo 288); y en (Sentencia de Primera Instancia), (TPIY, 10 de diciembre de 1998, párrafo 249).
} 
¿Es irrelevante para el acusado que apoyó y fomentó una empresa criminal conjunta su incapacidad para mejorar las condiciones del campo y prevenir los crímenes?

[Kvocka] alega que él no tenía autoridad, como miembro del servicio de seguridad, para influenciar o mejorar las condiciones de detención, incluyendo la calidad y cantidad de agua y comida, condiciones que fueron reconocidas por la Sala de Primera Instancia como elementos de tortura.

Al determinar la responsabilidad del acusado por crímenes cometidos como parte de una empresa criminal conjunta, no se trata de determinar lo que el acusado podría haber hecho, sino lo que hizo para contribuir a la empresa criminal conjunta. Que Kvocka haya sido incapaz de mejorar las condiciones de detención no tiene relevancia alguna para su responsabilidad penal, ya que su contribución a la empresa criminal conjunta comprendió crímenes que resultaron de que las condiciones de detención hayan sido establecidas.

Igualmente, no tiene fundamento el argumento de Radic de que él no puede ser considerado como responsable por crímenes que fue incapaz de impedir debido a la situación caótica del campo. La Sala de Primera Instancia encontró que el campo de Omarska funcionó como una empresa criminal conjunta y que Radic, a sabiendas y de manera substancial, contribuyó al funcionamiento del campo. Una vez que la Sala de Primera Instancia había establecido estos hechos, la conclusión de que Radic era responsable por los crímenes cometidos durante su participación en la empresa criminal conjunta fue correcta, independientemente de sus facultades para evitar la comisión de los crímenes individuales. A diferencia de la posición del artículo 7(3) del Estatuto, la responsabilidad por participar en una empresa criminal conjunta bajo el artículo 7(1) del Estatuto, no requiere prueba de que el perpetrador tiene la autoridad para impedir los crímenes. Radic es responsable, no porque no previno la comisión de los crímenes en cuestión, sino porque apoyó y fomentó una empresa criminal que permitió a personas maltratar a voluntad a los detenidos (TPIY, 2005b, párrafos 292, 295, 383).

Si una persona carece de suficiente autoridad para ser considerada un superior, ¿implica que carece de autoridad suficiente para hacer una 'contribución significativa' a una empresa? No se requiere que se demuestre responsabilidad del superior pero ¿una posición de liderazgo es solo relevante para determinar el ámbito de participación o es una circunstancia agravante?

En otro argumento relacionado, el Apelante Radic alega que no debería ser declarado culpable como co-perpetrador ya que la Sala de Primera Instancia lo exoneró de todos los cargos basados en la responsabilidad del superior. La sugerencia implícita en este argumento es que una persona que carece de suficiente autoridad para ser considerada un superior, necesariamente también carecería de autoridad suficiente para hacer una 'contribución significativa' a una 
empresa criminal conjunta sistémica. La Sala de Apelaciones hace notar que la participación en una empresa criminal conjunta, conforme al artículo 7(1) del Estatuto y la responsabilidad del superior conforme al artículo 7(3) del Estatuto, son categorías diferentes de responsabilidad penal individual, cada una con requisitos legales específicos. La responsabilidad por participar en una empresa criminal conjunta no requiere que se demuestre responsabilidad del superior ni prueba de alguna contribución substancial o significativa.

Aunque la posición de autoridad de jure o de facto no es una condición material requerida por ley bajo la teoría de la empresa criminal conjunta, la Sala de Apelaciones subraya que es un factor relevante para determinar el ámbito de participación del acusado en el propósito común (TPIY, 28 de febrero de 2005, párrafos 104 y 192).

La posición de líder político no se requiere para participar en una [empresa criminal conjunta], ni es una condición previa para el crimen de persecución. Por lo tanto, no es un elemento que establezca responsabilidad penal, y la Sala de Primera Instancia no lo ha considerado como tal al determinar la responsabilidad penal de Babic. Lo último deriva de su conducta al contribuir a la promoción del objetivo de la [empresa criminal conjunta] a través del crimen de persecución. De tal forma que los alegados presentados por la Defensa no evitan que la Sala de Primera Instancia tome en consideración las posiciones de liderazgo de Babic como una circunstancia agravante (TPIY, 2004c, párrafo 60).

\section{AUTORÍA - COAUTORÍA}

La primera posición respecto a este tema, y que generó incertidumbre en sus comienzos, fue la de la propia Sala de Apelaciones del TPIY y, en particular, la sentencia de 15 de julio de 1999 en el caso conocido como Tadic, en la que se afirma la naturaleza consuetudinaria de la doctrina de la ECC, ya que su aplicación deriva del Artículo 7 del TPIY y no definió con precisión la naturaleza jurídica, pues hace referencia a la misma utilizando expresiones como «coautoría» y "complicidad». Es decir, es importante observar que esta definición es el resultado de pretender justificar el carácter consuetudinario de la misma sobre la base de la aplicación de un sistema que no distingue entre autoría, participación (como fue previsto por los estatutos de Núremberg y Tokio) y formas de responsabilidad individual.

La Sala del TPIY, refiriéndose al tema de la autoría-coautoría, en decisión de 21 de mayo de 2003 en el caso Milutinovic, por primera vez dice que de acuerdo con la 
costumbre $^{42}$ internacional y el Derecho Penal Internacional, adopta un sistema dualista que distingue entre autoría y participación y construye el concepto de coautoría sobre la base de la doctrina de la ECC. Con posterioridad a esta determinación, la jurisprudencia de la Sala de Apelaciones de TPIY y del TPIR ha homologado tal postura en forma reiterada.

Durante años la jurisprudencia de los TPIY y TPIR ha presentado grandes dificultades para responder a las críticas que se hacen acerca de superar las enormes dificultades probatorias derivadas del gran número de miembros de las ECC, de sus importantes diferencias de rango y de su residencia en lugares tan distantes del país, además de preguntarse si se imputaría a todos los miembros de la ECC (dentro de los que pueden encontrarse altos dirigentes políticos y militares), e igualmente, si su responsabilidad sería en calidad de coautores por el conjunto de los actos de persecución durante años por decenas de miles de autores materiales.

En este punto es necesario acudir a la definición de la ECC, tanto en los sistemas de Common Law, como en la jurisprudencia inicial de los TPIY y TPIR, que exigen que los autores directos de los crímenes sean en todo caso parte de la ECC ${ }^{43}$. Acorde con lo anterior, la realización de los elementos objetivos del delito puede únicamente ser atribuida a aquellos miembros de la ECC que no lo realizan directamente (en el caso citado en precedencia, los altos dirigentes políticos y militares que planean y ponen en marcha la campaña asesinatos), pues quienes directamente lo ejecutan actúan de manera coordinada con aquellos en la implementación del plan común.

La construcción del concepto de coautoría, estructurado desde el punto de vista de la ECC, ha rechazado otros criterios que han sido utilizados tradicionalmente a nivel nacional para efectuar una distinción entre autores y partícipes en aquellos eventos en que los comportamientos delictuales se realizan a través de pluralidades de personas, como son aquellas infracciones denominadas de lesa humanidad. Sobre este punto, la Sala de Apelaciones ha rechazado en forma expresa los criterios que a continuación se señalan:

- Criterio objetivo-formal, propio de los sistemas de Common Law, que considera como coautores a quienes realizan personalmente, al menos, una parte de los elementos del tipo objetivo, siendo el resto de personas partícipes en el delito cometido por otros (TPIY, 1999, párrafos 191-192).

42 La costumbre como fuente de derecho internacional requiere: 1. una práctica general, uniforme y reiterada, y 2. opinio juris, demostrando que dicha práctica es llevada a cabo por un consentimiento de obligatoriedad.

43 Véase en particular, (TPIY, 17 de septiembre de 2003, párrafos 83-84). Véanse (TPIY, 15 de julio de 1999, párrafos 227 a 228); (TPIY, 17 de octubre de 2003, párrafo 158); y (TPIY-99-36-T, (TPIY, 1 de septiembre de 2004, párrafos 262, 264, 344 y 347). 
- Criterio objetivo-material del dominio del hecho, propio de algunos sistemas de tradición germánico-romano, en el cual solo tienen la condición de coautores quienes poseen un dominio positivo o negativo del hecho; positivo, debido a que realizan por sí mismos, o a través de un tercero que les sirve como instrumento, o negativo, debido al carácter esencial de la contribución asignada en la ejecución del plan común (TPIY, 2006a, párrafo 62).

Así, al aplicar el concepto a las muertes tradicionales (asesinatos y masacres) se encuentra que por mucho tiempo el TPIY ha reconocido, en particular, no solo en la parte probatoria sino en aquello que ha mencionado TPIY (29 de enero de 2007, párrafos 340-341) en donde se argumenta: «la perspectiva que podría llevar a responder a título de coautor a un soldado que expulsa de su casa a una familia de bosnio-musulmanes, teniendo en cuenta que en un periodo de cuatro años ha ocurrido la expulsión de cientos de miles de bosnio-musulmanes del territorio de la Republica Sprska» (TPIY, 3 de abril de 2007, párrafo 445). Si se tiene presente que la doctrina de la ECC no requiere que el nivel de contribución a la ejecución del plan común sea significativo, se podría estar corriendo el riesgo de trasformar la misma doctrina en una forma de responsabilidad colectiva, desconociendo tajantemente el principio de culpabilidad.

Otro escollo, tal como menciona Olásolo (2013), al momento de intentar dar aplicación a esta doctrina quedó en evidencia al tratarse de dirigentes políticos y militares de Camboya, casos que generaron intercambio de amicus curiae ante la Salas de Cuestiones Preliminares de las Salas Extraordinarias de las Cortes de ese país ${ }^{44}$ lo que demuestra que existe reticencia para construir un concepto de coautoría en derecho penal internacional sobre principios de la ECC.

\footnotetext{
44 Véanse, en particular, O Procurador vs Kaing alias EAV Duch, amicus Curia Brief do profesor Antonio Cassese e miembros de Journal of International Criminal da Xustiza Común en Doctrina Penal Empresarial, Las Cámaras Extraordinarias dos Tribunales de Camboxa, 001/18-07-2007 -ECCC/OCIJ (PTC 02) - D99-3-24, 27 de octubre de 2008; O Procurador vs Kaing alias EAV Duch, amicus Curia Presentada polo Prof Kai Ambos et al. Canto Proceso Penal Arquivo n 001/18-07-2007-ECCC/OCIJ (PTC 02), as Cámaras Extraordinarias dos Tribunais de Camboxa, 001/18-07-2007-ECCC/OCIJ (02 PTC)-D99-3-27, 27 de octubre de 2008; y O Procurador vs Kaing alias EAV Duch, amicus Curia Brief presentada polo Centro para los Derechos Humanos Pluralismo Jurídico, de la Universidad de McGill de Montreal (Quebec) Canadá, Cámaras Extraordinarias de los Tribunales de Camboya, 01 / 18-07-2007ECCC/OCIJ (PTC 02)-D99-3-25, 27 de octubre de 2008.
} 


\section{CONCLUSIONES}

La ECC se manejó hacia un modelo unitario de autor, que no establece diferencias claras y precisas entre los aportes individuales de cada una de las personas enjuiciadas, además no preciso oposiciones claras en cuanto responsabilidad de cada uno de los acusados, bajo las cuales insertó la responsabilidad, como tampoco realizó distinción en el grado de participación de cada uno de los acusados.

La ECC no fue clara en cuanto a los elementos de responsabilidad individual que fueron utilizados, ni en las categorías bajo las cuales se encuadró la responsabilidad de cada uno de los acusados ni en la discusión sobre la intensidad de participación de cada uno de ellos.

Una de las principales objeciones a la ECC tiene que ver con el fundamento normativo de la doctrina y con su validez material, enfocados con los principios del derecho penal. Su principal objeción consiste en que la ECC tiene que ver con el fundamento normativo de la doctrina y con la validez material de esta, a la luz de los principios generales del derecho penal.

La aplicación de la ECC podía constituir una violación al principio de nullum crimen sine lege, derivándose en forma implícita del Artículo 7.1 del Estatuto del TPIY, igualmente recordemos que la responsabilidad penal se soporta sobre el principio de la culpabilidad individual.

Se podría afirmar que ninguna de sus acepciones tiene soporte en el derecho consuetudinario, pues no mostró una práctica generalizada que justificara las reglas que estaba formulando. En la Empresa criminal Conjunta no tiene en ninguna de sus tres acepciones o modalidades soporte en derecho consuetudinario.

Otro aspecto sobresaliente para su aplicación está dado por el desconocimiento y aplicación del principio de culpabilidad, ya que esta figura va más allá del comportamiento individual y termina aplicando sanción a la persona por el mero hecho de pertenecer a un grupo.

La Empresa Criminal Conjunta en Colombia no correspondería con el tipo penal de concierto para delinquir agravado, ni tampoco lo podemos comparar con un crimen de lesa humanidad, lo cual no significa que los crímenes cometidos por la organización criminal sí lo sean.

La figura de la ECC ha sido bastante usada, pero dentro del marco de la macrocriminalidad no se han proferido condenas por mera asociación como hubiera sido lo pertinente en los Tribunales Militares de la Segunda Guerra Mundial.

En la ECC todas las personas que participan son autores; sin embargo, permite la graduación punitiva dependiendo de la intensidad con la que una persona haya contribuido al plan común. En los casos de coautoría, permite su incriminación cuando 
el exceso era previsible desde la óptica del plan común, es decir, cuando se encuentra de algún modo en el plan, referido para la tercera categoría de ECC - extendida.

El plan común tiene relevancia cuando analizamos la exigencia de que todos deben cumplir la intención de cometer los delitos integrados en el plan, esto tiene particular relevancia cuando analizamos la responsabilidad penal individual del dirigente, en la política, y de militares, en la comisión de crímenes de lesa humanidad, pues sería necesario que todos los autores, el director, los mandos medios y altos líderes políticos y militares estuvieran de acuerdo con el plan común, además se debería tener en cuenta la falencia probatoria que conlleva este asunto. Conforme a esta concepción tradicional, la realización de los elementos objetivos del tipo de los delitos integrados universalmente pueden ser atribuidos a aquellos miembros en la ECC que no los llevan a cabo directamente - dirigentes políticos y militares-, que planean y ponen en marcha, porque quienes los ejecutan directamente actúan de forma coordinada con aquellos en la implementación del plan común. Si aceptamos esta discusión, que los autores materiales y los mandos medios sean miembros de la ECC, pues es posible aplicarles que a un pequeño grupo de altos líderes políticos y militares, tras acordar el plan común, utilizan sus subordinados en las instituciones que dirigen para asegurar su eficacia.

Considero que esta figura de ECC puede entrar al debate jurídico en la forma de autoría y participación y, por ende, de responsabilidad penal dentro del marco de la ley de Justicia y Paz, pero no sería las más apropiada forma de imputación penal individual.

Por otro lado, no es extraño que algunos lleguen a pensar incluso que el caso de las llamadas «chuzadas» o escuchas ilegales por parte de funcionarios, al parecer del DAS, con la participación de altos dignatarios de la Presidencia de la República, se trate de una «empresa criminal». Estos ejecutaron intervenciones ilegales en la intimidad de magistrados, periodistas, líderes de la oposición y ciudadanos del común, mediante la modalidad de monitoreo técnico y continuación de las escuchas telefónicas; el fiscal del caso, en la diligencia de imputación adelantada en el mes de abril del año 2015, hace referencia a la figura de la «empresa criminal». En opinión del autor, parece más acertado hablar de la autoría mediata por dominio de la voluntad mediante aparatos organizados de poder.

En síntesis, se puede determinar que la empresa criminal conjunta o Joint Criminal Enterprise puede verse como parte de un modelo de imputación institucionalparticipativo o sistemático. Las más severas críticas por parte de académicos y litigantes en los tribunales $A d$ hoc han sido de quienes en su oportunidad sostuvieron que la ECC representa una extensión excesiva de los instrumentos internacionales, resultado del alto grado de activismo jurídico de los tribunales Ad hoc, poniendo en riesgo principios fundamentales dentro del proceso penal, como sería el principio de legalidad y responsabilidad penal individual. 


\section{REFERENCIAS}

Ambos, K. (2007). Joint Criminal Enterprise y responsabilidad del superior. En UNISED, (19), 39-78.

Aponte, A. (2010). Persecución Penal de crímenes internacionales: Diálogo entre la traducción nacional y el derecho internacional. Bogotá: Editorial Universidad Javeriana, Fukl, y Editorial Ibáñez.

Consejo de Seguridad de la Organización de las Naciones Unidas. (1993). Resolución 827 (25, mayo, 1993). Recuperado de: http://www.observatorioddr.unal. edu.co/ambitojuridico/catalogo_juridicojyp/estatuto_internacional_ adoptado_por_el_consejo_de_seguridad.pdf

Consejo De Seguridad de las Naciones Unidas. (1993). Estatuto Internacional adoptado por el Consejo de Seguridad de la Naciones Unidas para el TPIY. Recuperado de: https://www.icrc.org/spa/resources/documents/misc/ treaty-1993-statute-tribunal-former-yugoslavia-5tdm74.htm

Consejo De Seguridad de las Naciones Unidas. (1994). Estatuto del Tribunal Penal Internacional para Ruanda. Recuperado de: https://www.icrc.org/ spa/resources/documents/misc/treaty-1994-statute-tribunal-rwanda5tdmhw.htm

Olásolo, H. (2013). Tratado de autoría y participación en derechos penal internacional. Homenaje al profesor Augusto Ramírez Ocampo. Tirand lo Blanch.

Ramelli Arteaga, A. (2011). Jurisprudencia penal internacional aplicable en Colombia. Bogotá: GIZ, Universidad de los Andes y Embajada de la República Federal de Alemania en Bogotá.

Tadić, Duško. (2014). Artículo sobre el autor Dusko Tadić. Recuperado de: http:// es.wikipedia.org/wiki/ Duško_Tadić

Tribunal Penal Internacional para la ex Yugoslavia (TPIY). (1998). El Fiscal v. Anton Furundzija (Sentencia de Primera Instancia), 10 de diciembre de 1998. Países Bajos: Autor.

Tribunal Penal Internacional para la ex Yugoslavia (TPIY). (1999). El Fiscal v. Dusko Tadic (Sentencia de la Sala de Apelaciones), IT-94-1-A, 15 de julio de 1999. Países Bajos: Autor.

Tribunal Penal Internacional para la ex Yugoslavia (TPIY). (2000a). El Fiscal v. Blaskic (Sentencia de Primera Instancia), 3 de marzo de 2000. Países Bajos: Autor 
Tribunal Penal Internacional para la ex Yugoslavia (TPIY). (2000b). El Fiscal v. Anton Furundzija (Sentencia de la Sala de Apelaciones), TPIY-95-17/1-A, 21 de julio de 2000. Países Bajos: Autor.

Tribunal Penal Internacional para la ex Yugoslavia (TPIY). (2001). El Fiscal v. Omarska Kvocka et al. (Sentencia de Primera Instancia), ICTY-98-30/1-A, 2 de noviembre de 2001. Países Bajos: Autor.

Tribunal Penal Internacional para la ex Yugoslavia (TPIY). (2002) Setencia del, 29 de noviembre de 2002, párrafo 67.

Tribunal Penal Internacional para la ex Yugoslavia (TPIY). (2003a). El Fiscal v. Stakic (Sentencia de Primera Instancia), 31 de julio de 2003. Países Bajos: Autor.

Tribunal Penal Internacional para la ex Yugoslavia (TPIY). (2003b). El Fiscal v. Milorad Krnojelac (Sentencia de la Sala de Apelaciones), TPIY-97-25-A, 17 de septiembre de 2003. Países Bajos: Autor.

Tribunal Penal Internacional para la ex Yugoslavia (TPIY). (2003c). El Fiscal v. Simic, Tadic y Zaric (Sentencia de Primera Instancia), TPIY-95-9-T, 17 de octubre de 2003. Países Bajos: Autor.

Tribunal Penal Internacional para la ex Yugoslavia (TPIY). (2004a). El Fiscal v. Vasiljevic (Sentencia de la Sala de Apelaciones), TPIY-98-32-A, 25 de febrero de 2004. Países Bajos: Autor.

Tribunal Penal Internacional para la ex Yugoslavia (TPIY). (2004b). El Fiscal v. Krstic (Sentencia de la Sala de Apelaciones), 19 de abril de 2004. Países Bajos: Autor.

Tribunal Penal Internacional para la ex Yugoslavia (TPIY). (2004c). El Fiscal v. Babic (Sentencia de Primera Instancia), 29 de junio de 2004. Países Bajos: Autor.

Tribunal Penal Internacional para la ex Yugoslavia (TPIY). (2004d). El Fiscal v. Brdjanin (Sentencia de Primera Instancia), 1 de septiembre de 2004. Países Bajos: Autor.

Tribunal Penal Internacional para la ex Yugoslavia (TPIY). (2005a). El Fiscal v. Blagojevic y Jokic (Sentencia de Primera Instancia), 17 de enero de 2005. Países Bajos: Autor.

Tribunal Penal Internacional para la ex Yugoslavia (TPIY). (2005b). El Fiscal v. Omarska Kvocka et al. (Sentencia de la Sala de Apelaciones), TPIY-9830/1-A, 28 de febrero de 2005. Países Bajos: Autor.

Tribunal Penal Internacional para la ex Yugoslavia (TPIY). (2005c). El Fiscal v. Babic (Sentencia de la Sala de Apelaciones), IT-03-72-A, 18 de julio de 2005. Países Bajos: Autor. 
Tribunal Penal Internacional para la ex Yugoslavia (TPIY). (2005d). El Fiscal v. Limaj et al. (Sentencia de Primera Instancia), 30 de noviembre de 2005. Países Bajos: Autor.

Tribunal Penal Internacional para la ex Yugoslavia (TPIY). (2006a). El Fiscal v. Stakic (Sentencia de la Sala de Apelaciones), TPIY-97-24-A, 22 de marzo 2006. Países Bajos: Autor.

Tribunal Penal Internacional para la ex Yugoslavia (TPIY). (2006b). El Fiscal v. Krajisnik (Sentencia de Primera Instancia), IT-00-39-T, 27 de septiembre de 2006. Sobre la capacidad de la CCE de aprehender las distintas formas de macrocriminalidad. Países Bajos: Autor.

Tribunal Penal Internacional para la ex Yugoslavia (TPIY). (2007a). El Fiscal contra Thomas Lubanga Dyilo (decisión sobre la confirmación de los cargos Sala de Cuestiones Preliminares I), ICC-01/04-01/06-803-Ten), 29 de enero de 2007. Países Bajos: Autor.

Tribunal Penal Internacional para la ex Yugoslavia (TPIY). (2007b). El Fiscal v. Radoslav Brdanin (Sentencia de la Sala de Apelaciones), TPIY-99-36-A, 3 de abril de 2007. Países Bajos: Autor.

Van Der Marchitez. (2007). Empresa Criminal Conjunta: Posibilidades y limitaciones. 
